\title{
Studies on the Relationship between Social Security and Regional Economy Coordinated Development
}

\author{
Xiong Wei \\ Jingdezhen Ceramic Institute 333000
}

Keywords: social security; regional economies; coordinated development

\begin{abstract}
Act as the soft power for coordinated development of regional economies, a sound social security system can effectively adjust the regional economy structures, minimize the disparities and coordinate the development, so as to realize the stability of social progress. According to the status quo of domestic regional economies, this essay discusses the relationship between the social security system and regional economies coordinated development, and the model of simple linear regression is also built. By empirical analysis to the development situation of social security and coordinated development of regional economies in Jiangxi province in 2001 to 2011, it can be found that the former effectively promotes the later to a certain extent and provides theoretical basis and practical guidance to the government. Related suggestions to the development in the perspective of social security are also offered.
\end{abstract}

\section{Introduction}

The coordinated developing of regional economies is one of the big problems faced by all countries. China, with its vast territory, has a typical spread of economic basis, background culture and resource endowment.

Policies of reform and open give priorities to the eastern development, accelerating the domestic macro economy to some extent as well as the imbalances between regional economies which will seriously affect the national general welfare and the coordinated development of national economy and society, thus add instability to the regional ethnical unit and political affairs.

Present imbalances of domestic regional economies mainly present in the economic growth and income, economic structures and social development. The widening gap of income as well as social security services leads to the spring of regions in question and region questions. Then how to solve the imbalances and realize the regional coordinated development are the main questions urge to the domestic business circle and theory research.

The developing and perfecting of social security, the policy orientation of future coordinated development of regional economies, help to improve the public ability solving life risks, to narrow the wealth gap and adjust the economic structures. With this background, studies of the social security policies and regional economies coordinated development have become the focus of theorists both domestic and abroad.

This essay then has a certain practical guidance value analyzing the relationship between the social security and coordinated development of regional economies in the micro perspective on the point of successive refinement and perfecting of domestic social security system by a comprehensive view to the current situation.

\section{Research status}

\subsection{Research status abroad}

Current social security system is pushing the regional economies forward rapidly. There are a number of scholars studying the correspondence between social security and regional economies development, obtaining abundance fruit.

One of the representatives was what Aschauer (1989) first suggested that government social expenditures, being productive to some extent, can promote regional economic development [1]. And Osker Gans (1996) had his influential research by making detailed analyses to the relationship 
between social security and economic growth both positively and negatively through looking into the developing countries [2]. Issac Ehrlich and Jinyoung Kim (2005) elaborated the interreaction of the two sectors referring to related studies in the perspective of both theoretical and practical [3].

All the theories can be referred in studying social security and coordinated development of economies.

\subsection{Research status domestic}

With China's regional economies disparities worsening, scholars discussing the solutions to the imbalances paid attention to social security system. They made expanding studies on the basis of excellent theoretical results abroad and had their own progress.

Zhifeng Zhen (2010), defining the status of social security construction in economic developing, pointed out that a comprehensive social security system related should be the key strategy promoting the coordinated development of regional economies [4]. Wei Tan (2011) built the coupling coordination model and the evaluation index system of social security and economic development on the influential mechanism social security had to the economic development [5]. Chaoqun Liu (2013) then analyzed the regional disparities of domestic social security level and offered related countermeasures to the coordinated development [6].

\section{Research design}

\subsection{Variables selecting and model constructing}

To observe the relationship between social security and coordinated development of regional economies, this essay sets the GDP proportion of Jiangxi annual social expenditures as the independent variable $\mathrm{x}$, the coordinated development degree of regional economies as dependent variable y according to the related statistic yearbook of Jiangxi province.

The linear regression model of the two can be built:

$$
y_{t}=\lambda_{0}+\lambda_{1} x_{t}+\varepsilon_{t}
$$

Where $t$ refers to year, ${ }^{\lambda_{0}}$ refers to the constant term.

\subsection{Model Logistic testing}

To better analyze the relationship between social security and coordinated development of regional economies, Logistic testing to the model is needed. Details are referred to the logistic model two American scholars Cooper and Lead purposed in last century.

Suppose the logistic model of social security and coordinated regional economies as follows:

$$
y=\frac{1}{a+b c^{x}}
$$

In the formula, $a, b, c$ refers to the constant terms, and $a>0, b>0,0<c \neq 1$. Due to the inability of Model (2) to have direct regression tests, linear processing is necessary.

Have derivative on both side of Model (2) and convert it to $1 / y-a=b c^{x}$, then take the logarithm and get $\ln (1 / y-a)=\ln b+x \ln c$, and B will represent $\ln b, \mathrm{C}$ will represent $\ln c$, it can now convert to linear related model:

$$
Y=B+C x
$$

Variable parameters $\mathrm{B}$ and $\mathrm{C}$ can be determined using least square procedure.

\subsection{Marginal utility analysis}

Since the logistic function curve of the relationship between social security and regional economy coordinated development is " $\mathrm{S}$ " type, this essay made marginal analysis to the constructed linear relationship model to better study the role of the links, which means the influence on the coordinated development degree of regional economies social security expenditures variations had.

A specific method calculating marginal value is to solve the derivative of the function $y=f(x)$. The function's marginal maximum or minimize value can get out when the derivative is zero. Calculating the marginal value can guide the social security department making the best policy for the coordinated development of regional economies. 
The marginal analyses, which can better explain the facilitation effect social security (social security expenditure) had on the regional economies coordinated development (regional economies coordinated development degree), namely the changes of regional economies coordinated development degree had due to the unit change of social security expenditure proportion, it can be specified as the follows:

$$
f^{\prime}(x)=-b(\ln c) \times c^{x} /\left(a+b c^{x}\right)^{2}
$$

However, the promotion effect social security expenditure proportion had on the regional economies coordinated development degree changes at the inflection point of $\left(\mathrm{x}^{\prime}, \mathrm{y}^{\prime}\right)$, where the monotonicity varies. This point can be figured out when the second derivative of $y=f(x)$ is zero.

When the promotion point is before the reflection point, the increase of the proportion brings the growth of the coordinated development degree, and the later keeps growing with the former. When the promotion point is behind the refection point, however, the condition reversed. The more the expenditure proportion increases, the more the development degree decreases. When the two points coincide concisely, the effect gets the maximum.

Formula to get detailed refection point:

$$
f^{\prime \prime}(x)=-b(\ln c)^{2} \times d^{x} \times\left[\frac{1}{\left(H+c d^{x}\right)}+\frac{2 c d^{x}}{\left(H+c d^{x}\right)^{2}}\right] /\left(H+c d^{x}\right)
$$

In economics, elasticity represents the degree of the effects one varied element has on another element, specifically the percentage change in the later when the formal variation has changed $1 \%$. Therefore elasticity analysis can be applied to measure the pulling force to the coordinated development degree with $1 \%$ increase of social security expenditure proportion.

Detailed elasticity analysis expression:

$$
\lambda=f^{\prime}(x) \times \frac{x}{y}=-b(\ln c) \times \frac{x c^{x}}{\left(a+b c^{x}\right)}
$$

When $\lambda>1$, the developing speed of social security system is slower than the regional economies coordinated development, which is promoted by the former.

When $\lambda<1$, the developing speed of social security system is faster than the regional economies coordinated development, which promotes the former.

When $\lambda=1$, the two develops with the same pace.

\section{Empirical analysis}

The constructed linear analysis model was applied to make empirical analysis to the relationship between the developments of central logistic of Hebei province and its regional economies coordinated development. The essay selected the proportions of social security expenditure had in Jiangxi's GDP and the regional economies development degrees between 2001 and 2011 as empirical data to study their interreaction.

The development degrees of coordinated regional economies were mainly calculated by constructing measure model and related evaluation index system. The indexes were then checked out to determine the degrees.

Here are the detailed empirical data in Chart1:

Chart1 initial data of empirical analysis

\begin{tabular}{llll}
\hline Year & Social security expenditure proportion & $\begin{array}{l}\text { Regional economies } \\
\text { development degree }\end{array}$ & coordinated \\
\hline 2001 & 0.115 & 0.681 \\
2002 & 0.118 & 0.712 & \\
2003 & 0.104 & 0.709 & \\
2004 & 0.098 & 0.724 & \\
2005 & 0.102 & 0.783 \\
2006 & 0.096 & 0.829
\end{tabular}


Related trend graph of $\mathrm{x}$ (social security expenditure proportion) and y (regional economies coordinated development degree) can be made according to the dependent and independent dada. As shown in Fig.1.

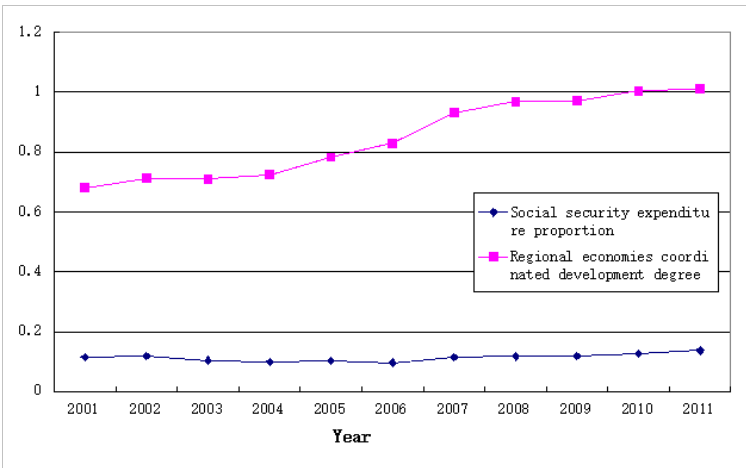

Fig. 1 related trend graph of $x$ and $y$

It can be seen from Fig.1 that there are linear relationships between the expenditure proportions and the developing degrees. Make regression analysis by least square method. Detailed data is shown in Chart 2.

Chart 2 regression analysis

\begin{tabular}{lllll}
\hline Variable & Coefficient & Std. Error & t-Statistic & Prob. \\
\hline$B$ & -8.612 & 1.354 & -6.387 & 0.000 \\
$C$ & 0.243 & 0.028 & 0.457 & 0.000 \\
R-squared & 0.874 & S.E. of regression & 1.833 & - \\
F-statistic & 155.331 & Durbin-Watson stat & 0.651 & - \\
\hline
\end{tabular}

Relation can be drawn from the regression data:

$y_{t}=0.243 x_{t}-8.612$

From the regression results, the fitting coefficient $\mathrm{R} 2=0.874$, and the equation has a relatively high fitting degree. There is little difference between the predicted value and the actual one and $\mathrm{T}$ test revealed that the equation had certain significance.

To have logistic testing to the relation model, the software Eviews and least square method can

be used to estimate the constant terms in the formula $y=\frac{1}{a+b c^{x}}$, $\mathrm{a} \approx 1 / 26790>0, \mathrm{~b} \approx 0.0046>0,0<\mathrm{c} \approx 0.999 \neq 1$, which conform to the regular pattern that the developing degree increase with the expenditure proportion in the economies term.

To have further analyses to marginal utility, since $0<\mathrm{c}<1$, then $\operatorname{lnc}<0$, and $\mathrm{f}^{\prime}(\mathrm{x})>0$, which illustrates that in Jiangxi province the coordinated development degree increases with the expenditure proportion growth.

Then get the function's second derivative to have the promotion effective inflection point, $\mathrm{x}=$ 0.174 , which means that when the social security proportion is below the point, the developing degree rise with its increase while decrease once the number pass the point. When the proportion meets with the point, the increase gets to its maximum.

\section{Conclusion}

Quantitative analysis to the relationship between social security and regional economies coordinated development was made in the essay, as well as the construction of the relation model of social security expenditure and regional economies coordinated development degree. It can be seen 
from the empirical analysis to Jiangxi province that the expenditure proportion does promote the developing degree and this has also been proved by logistic model testing in the essay.

The marginal analysis proved the regular rule that Jiangxi regional economies development degree rises with the increase of the expenditure proportion and gets to the maximum at the inflection point. When the elasticity coefficient is positive, the regional economies coordinated development varies in the same direction as social security.

\section{References}

[1] Alfred Greiner. Debt Sustainability in the European Monetary Union: Theory and Empirical Evidence for Selected Countries [J]. Oxford Economic Papers, 1996, 59:194 -218.

[2] Osker Gans. The Economics of Social Security in Developing Country: Positive and Nortive Consideration. Econolnics. 1996.Vol54.

[3] Issac Ehrlich, Jinyoung Kim: Social Security, Demographic Trend, and Economic Growth: Theory and Evidence from the International Experience. NBER Working Paper 11121, 2005:12-15.

[4] Yang SHAO,Jianguo ZHENG. The Panel Co-integration Analysis between the Logistics Industry and Economics Growth in China[J]. International Business and Management . 2011 (2)

[5] María Isabel Ayuda,Fernando Collantes,Vicente Pinilla. Long-run Regional Population Disparities in Europe During Modern Economic Growth: A Case Study of Spain[J]. The Annals of Regional Science . 2010 (2).

[6] Yigit Aydede. Aggregate Consumption Function and Public Social Security: the First Timeseries Study for A Developing Country, Turkey[J]. Applied Economics . 2008 (14). 